\title{
Descortesía en el ambiente laboral y maltrato al profesional médico
}

\author{
Discourtesy in the work environment and mistreatment of medical professionals
}

\section{Germán Valenzuela'}

Un buen trato físico, psicológico y emocional es importante para el buen desarrollo del trabajo médico, y ha sido asociado con un buen desempeño cuando es incluido como parte de los procesos de atención de calidad, centrados en los pacientes. ${ }^{1}$

El maltrato al profesional de la salud es un evento muy frecuente en la práctica de la medicina, desde el pregrado, el postgrado e inclusive en la práctica profesional fuera del ambiente académico, siendo común en los ámbitos sanitarios públicos y privados.

El maltrato al profesional médico es un término amplio que describe conductas problemáticas, sistemáticas y repetidas, como el menosprecio, la humillación pública, la intimidación, el abuso de poder, el acoso sexual, la discriminación y el abuso físico. Genera un ambiente laboral tóxico y no involucra a un concepto único, pues está relacionado con políticas organizacionales defectuosas, malas interacciones entre equipos de trabajo y hábitos individuales inapropiados. ${ }^{1,2}$

La descortesía, es una forma de maltrato en el centro de trabajo, la cual genera un ambiente laboral que dificulta el aprendizaje y el desempeño del equipo. Sin duda, tiene efecto en los resultados pues el $48 \%$ de médicos que experimenta este fenómeno lo asocia con una reducción en su esfuerzo laboral. Asimismo, el $66 \%$ mostró una disminución en sus resultados laborales y el $78 \%$ indicó que le generaba un menor compromiso con su organización. ${ }^{2}$ Los trabajadores de salud son dieciséis veces más

Médico internista y cardiólogo. Clínica Delgado, Lima. Investigador asociado, Universidad San Ignacio de Loyola, Lima, Perú.
Valenzuela G. Descortesía en el ambiente laboral y maltrato al profesional médico. Rev Soc Peru Med Interna. 2021;34(3):91-92.

https://doi.org/10.36393/spmi.v34i3.607

comúnmente víctimas de actitudes violentas en sus centros laborales que la población general; y, casi la mitad de médicos ha reportado abuso físico o psicológico en su ambiente laboral. Adicionalmente, existen instigadores a favor de actitudes violentas en el centro de trabajo, los cuales serían otros médicos, otros profesionales de la salud e inclusive los pacientes. Por desgracia, una cultura de descortesía, que fuera común en el sistema de salud, podría considerar normales a estas conductas que no serían aceptables en otros espacios laborales. ${ }^{3,4}$

En el ámbito académico, la tasa de reporte de actitudes violentas es muy baja pues menos de un tercio de estudiantes de medicina o residentes de medicina reporta los maltratos que habían sufrido porque los consideraban como un problema "poco significativo" c omo para reportarlos o, principalmente, para evitar problemas adicionales que pudieran empeorar más la situación. Sin embargo, ellos compartían sus experiencias negativas con otros estudiantes, amigos o familiares, pero nunca con las autoridades de los hospitales o de las universidades. ${ }^{3,6}$

Uno de los documentos mejor escritos sobre el maltrato al estudiante de medicina es el de Chávez, Ramos y Abreu, el cual evaluó la estructura general del maltrato, encontrando su direccionalidad (vertical/horizontal), su tipología (verbal, psicológico, académico, físico, sexual, racial, mediante tecnologías de información), el estudio del perpetrador (ámbito preclínico o clínico), el estudio del escenario (ámbito preclínico o clínico) y sus consecuencias (personales, educativas, profesionales y sociales). ${ }^{3}$

En el Perú, y a través de una encuesta aplicada a 281 estudiantes de medicina, se encontró que el 96,8\% de ellos percibió maltrato psicológico; $86,8 \%$ maltrato académico; $62,6 \%$ maltrato físico (el cual se incrementó durante el último ciclo de estudio) e inclusive maltrato sexual en 
el 20,6\%, el cual fue mayor en las mujeres, siendo los médicos docentes y los médicos residentes los principales agresores. ${ }^{5}$

El 83,9\% de los médicos residentes mexicanos encuestados reportó maltrato durante la residencia médica, siendo el más frecuente el maltrato psicológico, caracterizado por humillación, falta de respeto en el trabajo, la culpabilidad por errores de otros y los gritos. Adicionalmente, se reportó un maltrato académico (sobrecarga de trabajo usada como castigo, negación del acceso a la enseñanza como castigo), y en menor frecuencia maltrato físico (privación de acceso a los servicios higiénicos, alimentación o al sueño). Las consecuencias del maltrato fueron padecer o haber padecido burnout (89\%), depresión (71\%) y ansiedad (78\%), además de tener una influencia negativa en la calidad de atención de los pacientes (58\%). Este maltrato fue llevado a cabo por residentes de mayor jerarquía, seguidos de los médicos de planta y de los jefes de servicios, siendo las especialidades quirúrgicas más afectadas por ese fenómeno. ${ }^{6}$

En el ámbito profesional, se ha estudiado que los varones son los maltratadores más frecuentes, con mayor prevalencia en contra de las mujeres. Los servicios con el mayor número de actos violentos son los de cirugía general, seguidos de ginecología y medicina interna; $\mathrm{y}$, los servicios de oftalmología, pediatría, emergencia, cuidados intensivos, medicina general o medicina familiar con un menor índice de maltratos. Estos actos podrían ser ejecutados por médicos de mayor rango en contra de médicos que ellos considerarían como "menos experimentados", justificándolos por una elevada carga de trabajo, aunque claramente se deban a una falta de verdadero liderazgo y a la ausencia de una buena cultura organizacional. ${ }^{6,7}$

Se tiene que terminar con la nefasta cadena de actitudes descorteses y de maltrato al profesional médico. Es muy probable que los maltratadores hayan recibido también maltratos durante su formación, y que los continúen aplicando cuando tienen el poder, siempre relativo y temporal, a modo de venganza o para perennizar su "poder" en un ambiente sin reglas bien definidas. Algunos autores encuentran una similitud con la transmisión de la violencia intrafamiliar de una generación a la otra, o con la repetición de patrones aprendidos como el paso de víctima a victimario.

Por tanto, se proponen como alternativas de cambio:

1. Llevar a cabo un diagnóstico situacional, estableciendo un sistema de vigilancia continuo sobre los procesos de relacionamiento médicos, en los cuales debe primar el balance entre la búsqueda del logro de los objetivos grupales o corporativos, y el respeto al profesional médico.

2. Desarrollar una política de prevención del maltrato desde la Dirección o la Jefatura de Servicio.
3. Desarrollar verdaderos líderes dentro de una organización sanitaria, quienes tienen la responsabilidad de mantener y asegurar el trato respetuoso a los miembros de su equipo. Además de tener una sólida formación médica, los líderes deberán tener orientación hacia las ciencias sociales, respetando los conceptos de diversidad e inclusión para el logro y mantenimiento de una adecuada cultura organizacional.

4. Realizar un adecuado proceso de selección de los profesionales de la salud. Los conocimientos y los años de experiencia son importantes, pero también su historia personal (quejas, actitudes agresivas, historias de malos comportamientos o faltas contra la ética en otros centros laborales). Se deben explorar también las habilidades de comunicación, inteligencia emocional y competencia cultural de los nuevos miembros de los equipos.

5. Identificar y atender a los médicos maltratados a través de sistemas de reporte, arbitraje y conciliación.

6. Establecer mecanismos de apoyo a los médicos maltratados y un sistema de sanciones para los maltratadores.

7. Crear un comité para la construcción de relaciones sinceras y respetuosas entre profesionales médicos, a cargo de los mejores líderes de cada institución.

\section{REFERENCIAS BIBLIOGRÁFICAS}

I. Grover A,Applebaum N, Santen SA, Lee N, Hemhill RR, Goldberg S. Physician mistreatment in the clinical learning environment. The American Journal of Surgery. 2020, 220:276-28I.

2. Santosa KB, Sandhu G. Physician mistreatment and toxic teams: Incivility in clinical learning environments. The American Journal of Surgery. 2020;220:274-275.

3. Chavez-Rivera A, Ramos-Lira L, Abreu-Hernandez LF. Una revisión sistemática del maltrato en el estudiante de medicina. Gac Med Mex. 20I6; I52:796-8II.

4. Cheetham L, Turner C. Incivility and the clinical learner. Future Health Care Journal. 2020;7(2): I09-III.

5. Munayco-Guillern F, Camara-Reyes A, Muñoz-Tafur J, ArroyoHernández H, Mejia CR, Lem-Arce F, Miranda-Soberón UE. Características del maltrato hacia estudiantes de medicina de una universidad pública del Perú. Rev Peru Med Exp Salud Publica. 2016;33(I):58-66

6. Derive S, Casas-Martínez M, Obrador-Vera GT, Villa AR, Contreras D. Percepción del maltrato durante la residencia médica en México: medición y análisis bioético. Investigación en educación médica. 20I8;26(7):35-44

7. Keller S, Yule S, Zagarese V, Henrickson-Parker S. Predictors and triggers of incivility within healthcare teams: a systematic review of the literature. BMJ Open. 2020:10:I-I 5.

Lima, julio del 202I.

\section{CORRESPONDENCIA:}

Germán Valenzuela

german.v.valenzuela@gmail.com

Fecha de recepción: 28-07-202I.

Fecha de aceptación: 20-08-202I. 